\title{
Disability and physical activity in late life_-research models and approaches
}

\author{
E. Heikkinen
}

Published online: 22 March 2006

(C) EGREPA 2006

\begin{abstract}
Prevention of disability in late life has become a major public health concern, a key area of ageing research, and also an important target for the development of effective interventions. The increase in life expectancy and the resulting growth of the elderly population are also thought to be driving up the number of elderly people with disabilities. Despite the message that regular moderate physical activity has substantial health benefits even in very old age, older people remain largely sedentary. The most popular theoretical model for researching the development of disability is the disablement process, which is widely used, in the gerontological literature. The main pathway according to this model leads from diseases and injuries to impairments, functional limitations, and disability. This approach has been challenged most particularly by models, which emphasize the social construction and determinants of disability. Numerous physical exercise interventions have aimed at preventing impairments, functional limitations and disability, and at promoting independent living in late life. A review of the results of these interventions shows that exercise can indeed be effective in preventing impairments and functional limitations, but the evidence regarding the prevention of disability and dependency is inconclusive. The inconsistency of the results is related to differences in research models and approaches, cultural and other differences between the populations studied, and variability in research designs and methods, including definitions of key
\end{abstract}

\section{E. Heikkinen $(\square)$}

The Finnish Centre for Interdisciplinary Gerontology, University of Jyväskylä,

P.O. Box 35 (VIV), 40014 University of Jyväskylä, Finland e-mail: eino.heikkinen@sport.jyu.fi variables. In the future, research-addressing disability in late life needs to focus on the dynamic interactions between individuals and their social, physical, and cultural environment. Furthermore, randomized trials that are larger and longer than most existing studies of physical activity need to be conducted. Additional evidence can also be obtained by well-conducted observational studies focusing on the prevention of progressive disability related to chronic conditions. One of the key areas of development is in improving the definition of both independent (physical activity and exercise) and outcome (functional limitations, disability) variables. A further challenge is presented by the investigation of dose-response relationships, including both beneficial and possible adverse effects of exercise.

Keywords Disability prevention .

Physical activity and exercise · Research models .

Late life

\section{Introduction}

It is widely thought that the continuing growth of the elderly population is also driving up the number of older people with disabilities, as any possible compression of morbidity would not be enough to offset the effects of the rising numbers of older people. During the past century, the average life expectancy of Europeans has increased by 28 years, from 45 to 73 years. Before 1950, most of the gain in life expectancy was due to large reductions in death rates at younger ages. In the second half of the 20th century, improvements in survival after age 65 propelled the increase of 
longevity [29]. A striking observation is that for 160 years, best-performance life expectancy has steadily increased by a quarter of a year per year, and there is no evidence of a ceiling effect; life expectancy trajectories do not appear to be approaching a maximum. For women, the longest life expectancy (LE) in the European Union countries is recorded in France and Spain (82.9-83.0 years) and for men in Sweden and Iceland (77.9-78.7 years). The longest LE at 65 is for women in France (21.3 years in 2003) and for men in Iceland (18.1 years) [9]. Forecasts of healthy life expectancy (HALE) remain uncertain. While LE at 65 has increased substantially in most countries over the past 50 years, there are marked differences between countries with respect to the development of HALE. In some countries, the figures have gone up, in others they have remained unchanged, and in others still, they have even decreased. Increases in life expectancy of a few years can produce large increases in the numbers of older people, augmenting the needs for health and social care and other social needs, including involvement in physical activities.

This paper aims, first, to give examples of the occurrence of disabilities and levels of physical activity in late life. The second part of the paper summarizes the most widely used models and approaches in researching the development of disability in late life and the possible roles of physical activity. The inherent complexity in the development of disability in late life challenges the research community in the ageing field to undertake new studies to gain a better understanding of the dynamics of disability development and to produce evidence-based knowledge for the promotion of physical activity. A research agenda for this end is suggested in the final section.

\section{Disability in late life}

Functional decline and disability seem to be typical uncomfortable features of the individual ageing process. According to Zola [48], "the issue of disability for individuals is not whether but when, not so much which one, but how many and in what combination". Disability means difficulty or dependency in carrying out daily self-care activities, living independently in a home, and carrying out essential social roles. Disability decreases quality of life and increases the risk of hospitalization, nursing home admission, home help, and premature death [3]. The economic burden imposed by disability on society is great. It has been estimated that the use of social and health services increases in parallel with the increase in various disabilities [36].

There is no consensus about the operationalization of disability. Various measures and scales are used to either assess physical, emotional or social disability among older people [22]. This is obviously one major source of difficulty in assessing disability as an outcome of intervention studies.

The most often used measures include self-reports on disability in self-care tasks, physical activities of daily living (PADL), and in tasks of household management, as well as instrumental activities of daily living (IADL). Approximately $20 \%$ of people aged 70 or above, and $50 \%$ of people aged 85 and above, report difficulties in basic activities of daily living. The prevalence of disabilities is higher among women than men, and life expectancy with disabilities at 65 years of age is also longer in women [36]. The Evergreen study [24] among older Finnish people found that the proportion of 75-year-old men who needed help to perform all seven instrumental activities of daily living was $14 \%$ among all men at baseline, and increased over the 5 -year follow-up from 11 to $26 \%$ among the survivors. The corresponding figures for women were 32,19 , and $42 \%$.

Recent reports show that about $20 \%$ of older US adults have chronic disabilities. Underlying these disabilities, $7-8 \%$ have severe cognitive impairments, one third have mobility limitations, $20 \%$ have vision problems, and 33\% have hearing impairments [11].

Despite recent improvements in disability and functioning in late life, there is an urgent need in several countries to develop effective means for recognizing the risk factors of disability in older adults as well as effective interventions. Disability prevention has become an important public health concern. To quote Virchow: "Mass problems require mass solutions" [8].

\section{Physical activity in late life}

Overall physical activity decreases with advancing age. This concerns both physical activities in daily living and physical exercise, including planned, structured, and repetitive bodily movements with the intent of improving one or more components of physical fitness. The physical activity level of an individual can be based on frequency, duration or intensity of participation, or energy expenditure in a range of household, leisure, or exercise activities.

Physical inactivity is nothing short of an epidemic among older adults today, even though there is no 
consensus on the definition of physical inactivity or a sedentary lifestyle. Research results vary due to cultural differences and differences in the methods of assessing physical activity. An earlier study conducted in 11 countries among about 17,000 people aged $60-89$ years showed that physical exercise for fitness (assessed in terms of the proportion of interviewees who walked for fitness and the number of kilometers walked for fitness per week) was much more common among people living in northern and western Europe than in southern Europe [17].

In the US, it has been estimated that only $12 \%$ of adults aged 75 and over engage in 30 min of moderate physical activity five or more days a week, and $65 \%$ report no leisure physical activity at all [43].

A comparative study among three Nordic community-dwelling 75-year-old populations [28] showed that about one third could be regarded as sedentary (physical activity limited to mainly sitting in one place or practicing only light physical activity), whereas about $40 \%$ were regarded as moderately active (moderate physical activity for about $3 \mathrm{~h}$ a week), and about one quarter as physically active (moderate physical activity for more than $4 \mathrm{~h}$ a week or intense physical activity up to $4 \mathrm{~h}$ a week, or active sports for at least 3 $\mathrm{h}$ a week). Among older adults, there are enormous cultural differences in physical exercise.

The definition and assessment of physical inactivity and sedentary lifestyle vary from one study to another. It is, however, quite obvious that physical inactivity is endemic among older people and that it is therefore an important concern for research and public health policies and programs. However, research results on the effectiveness of physical activity promotion for older adults are inconsistent [5]. These inconsistencies lend support to the statement by Conn et al. [5] that on the basis of their integrative review of physical activity intervention research, "there is a vital need for rigorously designed studies to contribute to this science".

\section{Development of disability}

The disablement process The most widely used conceptualization of disability, the disablement process, is based on the concept initially proposed by Nagi [27] and further elaborated among others by Vebrugge and Jette [44]. It is assumed that the main pathway is based on a sequence of events proceeding from the acquisition of pathology (acute or chronic diseases, injury) to the generation of impairments manifested at the level of organs and body systems (e.g., decreased muscle strength, flexibility, aerobic capacity, and cognitive capacity), which lead to functional limitations at the level of the organism as a whole (e.g., restrictions in walking, stair climbing, general mobility skills, and balance), and finally to disability (e.g., difficulty or inability to manage activities of daily life such as personal care, household chores, job, and leisure activities within the context of the environment and its challenges). In 1980, the WHO [45] published a related model with the sequence of diseases leading to impairment, disability, and handicap. This model was further revised in 2001. This work led to the publication of the International Classification of Health and Function [46], which also aims at stimulating researchers to provide professionals in health care with appropriate tools to deal with the prevention of handicaps.

The disablement model has been widely used in ageing research, and there is accumulating empirical evidence describing the progression from disease to disability [13]. Disease burden (which often means more than one disease per elderly person) is an important risk factor for impairments, functional limitations, and subsequent disability [41]. A recent study has shown that newly reported chronic conditions: dementia, stroke, psychological disorders, low body mass index, and obesity are significantly and consistently associated with functional dependency among elderly people [47] highlighting the potential benefits of prevention and also the efficient management of chronic conditions from the point of view of disability prevention.

Disability in late life is also predicted by midlife grip strength [34] and customary walking speed [14]. Furthermore, recent evidence suggests that the accumulation of deficits across multiple domains (coimpairment, e.g., in strength and balance) may better explain the development of functional limitations than decline in a single domain [33].

The main pathway of the disablement process has also attracted its critics, who say it is overly simplistic and places too much emphasis on medical aspects. Biomedical diseases are often inadequately considered to be common to humans and to social groups, whereas diseases have been defined not only by anatomical, physiological, and biochemical variables, but also by physical, cultural, and social factors. Diseases are therefore neither invariable nor universal or suprahistorical. Furthermore, it seems there is no linearity between the type and severity of diseases and their consequences [2], and the unidirectional causal links of pathology, impairment, and disability do not adequately describe processes that are often nonlinear and involve feedback loops. 
The decline and loss paradigm often ignores the broader needs and aspirations of older people who suffer from disabilities and, in so doing, reinforces the biomedicalization of ageing.

It also appears that certain psychological factors, such as poor self-efficacy, low self-confidence, poor coping strategies, and fatalism predict the development of disability [4] but these are not usually included in research models.

According to Nagi's original conceptualization, disability can be defined as a gap between a person's abilities and the environment's requirements [27]. A modification of the disablement process takes into account both the psychosocial and medical aspects of old age disability. This is the foundation of the sociomedical model of disablement, which looks beyond the main disablement pathway to broader personal risk factors within a physical and social environment that also contribute to disability development [44].

Identical physical and mental conditions may result in different patterns of disability, depending for example on the individual's housing conditions or family structure. On the other hand, a similar type of disability may arise from different types of health conditions. The fact that disability is unequally distributed within populations indicates that disability has a distinct sociogenic component [35]. Persons in a low socioeconomic position lack both the internal and external resources that are needed to prevent the transformation of impairments and functional limitations into disability. They also live in physical environments that present various obstacles to participation in social and physical activities [1,39]. Recently, evidence has accumulated to suggest that community differences in what has been referred to as social capital (cooperative network of social relationships, levels of trust, perceived reciprocity, and membership of various types of groups or associations) have significant independent effects on disability and health [18] which can also predict the onset of disability.

The fundamental paradigm difference in disability development perceptions is presented in a schematic form in Fig. 1. Still, some researchers take the view that disability may have a physical background but is socially constructed by the disabling environment: societies produce disabilities out of impairments in different ways.

In this context, disability does not reside solely within individuals who have impairments and functional limitations, but also in the social, physical, economic, and political environment. There are numerous social theories and models of disability $[32,38]$.

\section{DEVELOPMENT OF DISABILITY}

Physically based

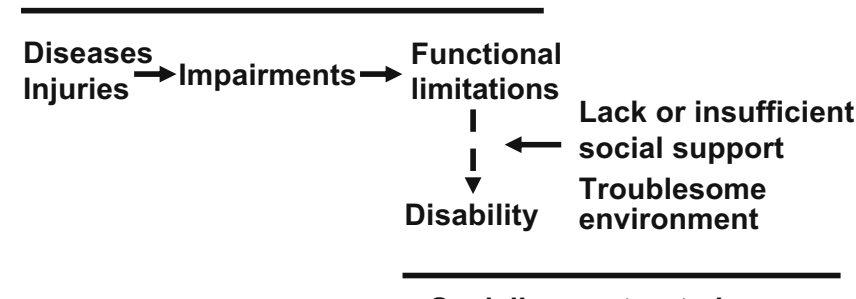

Socially constructed

Fig. 1 Development of disability seen either as physically based according to a medical model or as socially constructed according to a social model

The key role of social factors in the construction of disability is explicitly emphasized in critical theory [19], which regards the problems faced by disabled people as the product of an unequal society. Prejudice and discrimination disable and restrict people's lives more than impairments do (e.g., problems in public transportation). By emphasizing deficiency and dependency, the medical profession tends to reinforce these ideologies, without noticing that "independent living is not doing things by yourself, it is being in control of how things are done". Clearly, disability studies that apply the social model approach also need to open up to new perspectives and generate new and more precise accounts of disabled people's lives, including the social exclusion they face. At the same time, though, it can be argued that the strength of disability studies focusing on old age has been demonstrated as scholars from other areas have drawn from socialmodel and rights-based analyses [38].

\section{Physical activity in prevention of disability in late life}

There is a wealth of evidence about the adverse health outcomes of physical inactivity and the health benefits of physical exercise in older people, even among those who shift from a sedentary lifestyle to at least moderate levels of physical activity. This has been documented in several literature reviews and metaanalyses [5, 6, 21-23].

Exercise reduces the risk of mortality in general and the incidence of various diseases in particular.

It has also been observed that older individuals with established chronic conditions such as osteoarthritis can benefit from an exercise programme. Furthermore, exercise at moderate intensity is a significant predictor of positive subjective health, whereas physically inactive elderly people are at greater risk of developing 
depression than those who are physically active. Research results show that exercise improves strength, aerobic capacity, flexibility, standing balance, and walking. Less is known about the effects of exercise on various psychological domains, such as cognitive functioning, self-esteem, self-efficacy, coping strategies, beliefs, and emotions.

However, research findings on the effects of physical activity and exercise on the prevention of disability and loss of independence have been inconsistent [21-23].

The best-evidence approach [21] showed that "exercise-particularly walking-increases muscle strength and aerobic capacity and reduces functional limitations. It is less clear, however, whether physical activity or exercise prevents or minimizes physical disability". Prospective and experimental studies have produced conflicting evidence; several well-conducted prospective studies have shown that physical activity has a beneficial effect in terms of minimizing disability, whereas the majority of experimental studies have revealed no improvements in disability. A literature review on experimental and quasiexperimental aerobic and resistance exercise interventions showed that "late-life exercise clearly improves strength, aerobic capacity, flexibility, and physical function. Existing scientific evidence, however, does not support a strong argument for late-life exercise as an effective means of reducing disability" [22].

These inconsistencies may arise from various sources. Differences in research designs, populations studied, and methods employed are one such source. Many studies are based on "standard empiricism" and lack a sound theoretical foundation, and definitions of the main concepts and their relationships are often inadequately described. There are also inconsistencies in the definition of both the independent variables (physical activity, exercise) and outcomes (functional limitations, disability), as recently described by Guralnik and Ferrucci [13], Keysor [21] Fried et al. [12], and Haley et al. [15]. The differences seen between the results of experimental and observational studies may have to do with differences in follow-up times, which in experimental studies vary from a few months to a couple of years, whereas in observational studies, the time frame extends from a few years to several decades. This difference in follow-up time may be of particular importance when the concern is with the effects of exercise on the prevention of diseases underlying disability. It is also necessary to consider recent findings which demonstrate that genetic factors determine, for example, about one third of the variation in muscle strength [42] and balance [30].

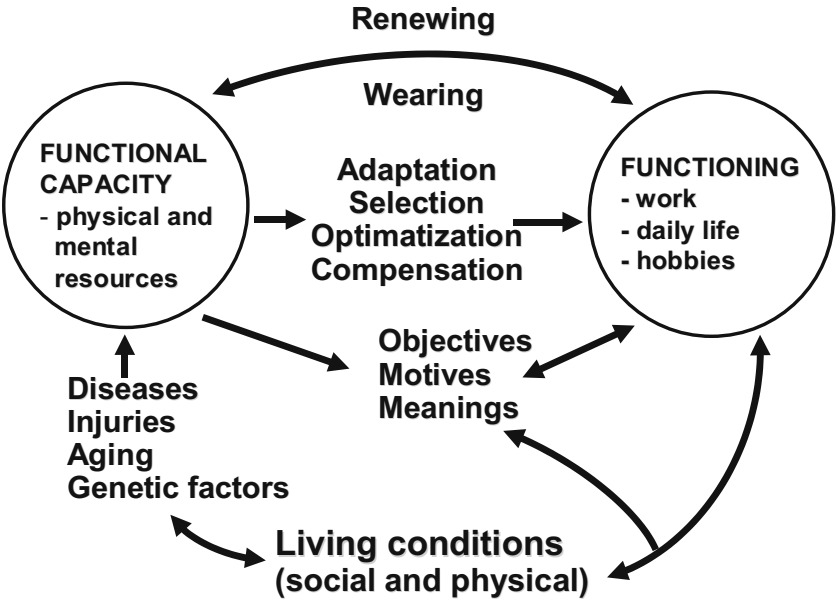

Fig. 2 An integrative model presenting modalities and processes assumed to affect the development of an individual's functional capacity and disability over the life course

One area that has largely been neglected in previous research is the complex interplay between individuals and their social and physical environment, not only among older people but in most adults [37]. Socioecological models of health promotion have recently gained growing attention as a way to achieve a better understanding of the relative influence that the social and physical environment and policies have on physical activity [31]. It is suggested that a modification of social, economic, and environmental factors may yield greater health benefits than individual lifestyle approaches, and that such interventions may be necessary for effective lifestyle approaches [25]. Individual behavior is also affected by cultural and other contextual factors, such as attitudes, beliefs, motivations, and barriers related to exercise and organization and the availability of services [7].

The development of disability is a complex, dynamic process in which underlying individual and environmental factors interact with one another not only along unidirectional causal chains, but also via various feedback loops. This process is summarized in Fig. 2, which aims to demonstrate the interplay of different individual and environmental factors taking place when individuals try to maintain sufficient balance between their resources, activities based on their objectives, and the effects of the social and physical environment [16].

\section{Challenges for further research}

Prevention of disability in late life has become a major public health concern, a key area of ageing research and a target for the development of effective policies and programs. 
Given the large number of disability determinants, it is clear that no single intervention can hope to modify more than a few of them. Based on the current scientific literature, future research ought to consider the following issues:

- Randomized trials that are larger and longer than most existing studies of physical activity are needed to address the issue of how to prevent disability in late life. Additional evidence can also be obtained by well-conducted observational studies.

- It is essential to improve and perhaps achieve consensus on the definition of both independent (physical activity and exercise) and outcome (functional decline, disability) variables. Guralnik et al. [13] have emphasized the importance of measuring functional limitations by means of either selfreport or standardized objective measures of physical performance to better understand the dynamics of the pathway leading from disease to disability. The mechanisms connecting, for example, muscle strength to the onset of disability is also an important target for research.

- When addressing disability, we should also directly target the interactions between individuals and their environment. This will require new tools of data collection. More attention should also be given to different psychological and psychosocial factors as both personal resources and behavior modifiers. Advanced theoretical models comprising the essential modalities and their complex relationships in the development of disability in late life are needed to guide thinking and planning of required research designs.

- There is also a need for studies aimed at preventing or delaying functional decline and disability in frail older persons [10], and attention should also be placed to coimpairments as predictors of functional decline and subsequent disability

- Dose-response issues, concerning physical activity and health, present a difficult challenge for research in general and research among older people in particular [40]. Older people may have many physical characteristics other than aerobic capacity that preclude the accurate measurement of fitness or strength. The energy cost of activities with assistive devices may be significantly higher than predicted, and the assessment of exercise intensity is problematic.

- The evidence-based symposium on dose-response issues concerning physical activity and health [20] developed several recommendations to improve the quality of research in this field. The recom- mendations, which are also relevant regarding people at late life, include the development of gold standards for the precise field measurement of physical activity, the evaluation of the health effects of multiple levels of physical activity, volume, intensity and fitness, the application of innovative statistical procedures, the assessment of potential adverse effects of physical activity, and study populations representative of all ages, both sexes, ethnic groups, and with a variety of health states. Furthermore, attention ought to be placed to newly recognized, interindividual variability in the response to physical activity and its genetic basis.

\section{References}

1. Balfour JL, Kaplan GA (2002) Neighbourhood environment and loss of physical function in older adults: evidence from the Alameda County Study. Am J Epidemiol 155:507-515

2. Bauman AE, Smith BJ (2000) Healthy ageing: what role can physical activity play? Med J Aust 173:88-90

3. Burden of Disease Network Project (2004) Disability in old age: final report, conclusions and recommendations. Jyväskylä: Jyväskylä Univ. Press, http://www.jyu.fi/BURDIS

4. Caplan LJ, Schooler C (2003) The roles of fatalism, selfconfidence, and intellectual resources in the disablement process in older adults. Psychol Aging 18:551-561

5. Conn VS, Minor MA, Burks KJ, Rantz MJ, Pomeroy SH (2003) Integrative review of physical activity intervention research with aging adults. J Am Geriatr Soc 51:1159-1168

6. Cress ME, Buchner DM, Prohaska T, Rimmer J, Brown M, Macera C, DiPietro L, Chodzko-Zajko W (2005) Best practices for physical activity programs and behavior counseling in older adult populations. J Aging Phys Act 13:61-74

7. Dergance JM, Calmbach WL, Dhanda R, Miles TP, Hazuda HP, Mouton CP (2003) Barriers to and benefits of leisure time physical activity in the elderly: differences across cultures. J Am Geriatr Soc 51:863-868

8. Ebrahim S (2002) Ageing, health and society. Int J Epidemiol 31:715-718

9. Eurostat (2005) The Statistical Office for European Communities

10. Ferrucci L, Guralnik JM, Studenski S, Fried LP, Cutler GB, Walston JD (2004) Designing randomized, controlled trials aimed at preventing or delaying functional decline and disability in frail, older persons: a consensus report. J Am Geriatr Soc 52:625-634

11. Freedman VA, Martin LG, Schoeni RF (2002) Recent trends in disability and functioning among older adults in the United States. JAMA 288:3137-3146

12. Fried LP, Ferrucci L, Darer J, Williamson JD, Anderson G (2004) Untangling the concepts of disability, frailty, and comorbidity: implications for improved targeting and care. J Gerontol Med Sci 59:255-263

13. Guralnik JM, Ferrucci L (2003) Assessing the building blocks of function: utilizing measures of functional limitation. Am J Prev Med 25:112-121 
14. Guralnik JM, Ferrucci L, Simonsick EM, Salive M, Wallace RB (1995) Lower extremity function in persons over the age of 70 years as a predictor of subsequent disability. N Engl J Med 332:556-561

15. Haley SM, Jette AM, Coster WJ, Kooyoomjian JT, Levenson S, Heeren T, Ashba J (2002) Late life function and disability instrument: development and evaluation of the function component. J Gerontol Med Sci 57A:M217-M222

16. Heikkinen E (2000) A paradigm shift: from disease to health orientation. Aging Male 3:171-176

17. In: Heikkinen E, Waters WE, Brzezinsky ZJ (eds) (1983) The elderly in eleven countries: a sociomedical survey. World Health Organization, Copenhagen

18. Kawachi I, Kennedy BP, Glass R (1999) Social capital and self-rated health: a contextual analysis. Am J Publ Health 89:1187-1192

19. Kennedy J, Minkler M (1998) Disability theory and public policy: implications for critical gerontology. Int $\mathrm{J}$ Health Serv 28:757-776

20. Kesaniemi YA, Danforth E, Jensen MD, Kopelman PG, Lefebvre P, Reeder BA (2001) Dose-response issues concerning physical activity and health: an evidence-based symposium. Med Sci Sports Exerc 33:S351-S358

21. Keysor JJ (2003) Does late-life physical activity or exercise prevent or minimize disablement? A critical review of the scientific evidence. Am J Prev Med 25:129-136

22. Keysor JJ, Jette AM (2001) Have we oversold the benefit of late-life exercise? J Gerontol Med Sci 56A:M412-M423

23. Latham N, Anderson C, Bennet D, Stretton C (2003) Progressive resistance strength training for physical disability in older people. Cochrane Database Syst Rev 2: CD002759

24. Laukkanen P, Sakari-Rantala R, Kauppinen M, Heikkinen E (1997) Morbidity and disability in 75-and 80-year-old men and women: a five-year follow-up study. Scand J Soc Med 53:79-106 (Suppl)

25. Lawlor DA, Ness AR, Cope AM, Davis A, Insall P, Riddoch C (2003) The challenges of evaluating environmental interventions to increase population levels of physical activity: the case of the UK National Cycle Network. J Epidemiol Community Health 57:96-101

26. Minaire P (1992) Disease, illness and health: theoretical models of the disablement process. Bull World Health Organ 70:373-379

27. Nagi SZ (1976) An epidemiology of disability among adults in the United States. Milbank Mem Fund Q Health Soc 54:439-467

28. NORA studies (2002) Nordic research on ageing: the fiveyear follow-up of the functional capacity of 75-year-old men and women in three Nordic localities. Aging Clin Exp Res 14 (Suppl)

29. Oeppen J, Vaupel W. Broken limits to life expectancy. Science 296:1029-1031

30. Pajala S, Era P, Koskenvuo M, Kaprio J, Tolvanen A, Heikkinen E, Tiainen K, Rantanen T (2004) Contribution of genetic and environmental effects to postural balance in older female twins. J Appl Physiol 96:308-315
31. Pikora T, Giles-Corti B, Bull F, Jamrozik K, Donovan R (2003) Developing a framework for assessment of the environmental determinants of walking and cycling. Soc Sci Med 56:1693-1703

32. Putnam M (2002) Linking aging theory and disability models: increasing the potential to explore aging with physical impairment. Gerontologist 42:799-806

33. Rantanen T, Guralnik JM, Ferrucci L, Leveille S, Fried LP (1999) Coimpairments: strength and balance as predictors of severe walking disability. J Gerontol Med Sci 54A:M172M176

34. Rantanen T, Guralnik JM, Fley D, Masaki K, Leveille S, Curb JD, White L (1999) Midlife hand grip strength as a predictor of old age disability. JAMA 281:558-560

35. Rautio N, Heikkinen E, Ebrahim S (2005) Socioeconomic position and its relationship to physical capacity among elderly people living in Jyväskylä, Finland: five- and ten-year follow-up studies. Soc Sci Med 60:2405-2416

36. Salive ME, Guralnik JM (1997) Disability outcomes of chronic disease and their implications for public health. In: Hickey T, Speers MA, Prohaska TR (eds) Public health and aging. The Johns Hopkins Univ. Press, Baltimore, pp 87-106

37. Sallis JF, Bauman A, Pratt M (1998) Environmental and policy interventions to promote physical activity. Am J Prev Med 15:379-397

38. Shakespeare T (2005) Review article: disability studies today and tomorrow. Sociol Health Illn 27:138-148

39. Shumway-Cook A, Patla AE, Stewart A, Ferrucci L, Ciol MA, Guralnik JM (2002) Environmental demands associated with community mobility in older adults with and without mobility disabilities. Phys Ther 82:670-681

40. Spirduso WW, Cronin DL (2001) Exercise dose-response effects on quality of life and independent living in older adults. Med Sci Sports Exerc 33(Suppl 6):S598-S608

41. Stuck AE, Walthert JM, Nikolaus T, Bula CI, Hohmann C, Beck JC (1999) Risk factors for functional status decline in community-living elderly people: a systematic literature review. Soc Sci Med 48:445-469

42. Tiainen K, Sipilä S, Alen M, Heikkinen E, Kaprio J, Koskenvuo J, Tolvanen A, Pajala S, Rantanen T (2005) Shared genetic and environmental effects on strength and power in older female twins. Med Sci Sports Exerc 37:72-78

43. U.S. Department of Health and Human Services (2000) Healthy people 2010: understanding and improving health, 2nd edn. Government Printing Office, Washington, DC, US

44. Verbrugge LM, Jette AM (1994) The disablement process. Soc Sci Med 38:1-14

45. WHO (1980) International classification of impairments, disabilities and handicaps. World Health Organization, Geneva

46. WHO (2001) International classification of functioning, disability and health. World Health Organization, Geneva

47. Wolff JL, Boult C, Boyd C, Anderson G (2005) Newly reported chronic conditions and onset of functional dependency. J Am Geriatr Soc 53:851-855

48. Zola IK (1993) Self identity and the naming question: reflections on the language of disability. Soc Sci Med 36:167-173 